\title{
Modeling and construction optimization of a modular TFM with an outer rotor
}

\author{
M. Kowol • M. Lukaniszyn • K. J. Latawiec
}

Received: 2 May 2009 / Accepted: 13 July 2010 / Published online: 28 July 2010

(c) The Author(s) 2010. This article is published with open access at Springerlink.com

\begin{abstract}
This paper presents a new optimal design of the magnetic circuit for a modular reluctance transverse flux motor (TFM) with an outer rotor. The design aims at maximizing the average electromagnetic torque and minimizing the ripple torque, with the two requirements appropriately weighted depending on a specific application of the motor. A precise numerical FEM model of the motor, developed in the Flux3D program, is coupled with a MATLAB-based evolutionary algorithm for constrained optimization of construction parameters of the magnetic circuit. The fundamental role of a type of an optimization criterion function is emphasized and a new effective criterion function is introduced. The performance of an optimal motor prototype constructed according to the optimum design fully confirms the usefulness of the presented approach.
\end{abstract}

Keywords Transverse flux motor · 3D field modeling · Evolutionary optimization . Optimization criteria Electromagnetic torque ·

Ripple torque

\section{Introduction}

Transverse flux motors (TFMs) have recently attracted remarkable interest both from the academia and various industrial environments $[1,3,4]$. The low-speed motor is

M. Kowol · M. Łukaniszyn · K. J. Latawiec $(\bowtie)$

Department of Electrical, Control and Computer Engineering,

Opole University of Technology, Opole, Poland

e-mail: k.latawiec@po.opole.pl

M. Kowol

e-mail: m.kowol@po.opole.pl

M. Łukaniszyn

e-mail: m.lukaniszyn@po.opole.pl characterized by a high ratio of the electromagnetic torque to its volume $[18,19,23,24]$, leading immediately to various high-torque transmission-free applications, not to mention electric wind generators [1], electric (and hybrid) drives [5] and in-wheel drives $[9,11,16]$. On the other hand, there has been a tremendous effort devoted to the problem of reduction of accompanying torque pulsations, often referred to as the ripple/cogging torque, which has been plaguing not only TFMs $[6-8,14,15,21,22,25]$. Reduction of the ripple torque is certainly welcome in the above high-torque implementations, but it is vital in modern control and robotics applications [2]. Simultaneous maximization of the average electromagnetic torque and minimization of the ripple torque is a contradicting task which can only be solved in a compromise way for a specific TFM construction. A new construction optimization approach offered in this paper enables to flexibly fulfill the average torque versus ripple torque compromise depending on a specific TFM application. An evolutionary optimization algorithm is run over admissible sets of a number of construction parameters of the magnetic circuit of the motor.

A prerequisite for an optimal design of the electromagnetic field distribution in special-construction motors like TFMs is the availability of an accurate, numerical, necessarily 3D model of the field. An effective tool for the purpose is the 3D FEM and an adequate modeling environment is the Flux3D program. The program is coupled with the MATLAB package which provides means for the development of an evolutionary optimization algorithm. It should be stressed that the employed modeling and optimization tools help to avoid constructing and verifying a number of physical motor prototypes, which could be very expensive.

The rest of the paper is structured as follows. A construction of a basic TFM prototype to be optimized and its numerical model are presented in Sects. 2 and 3, respectively. 


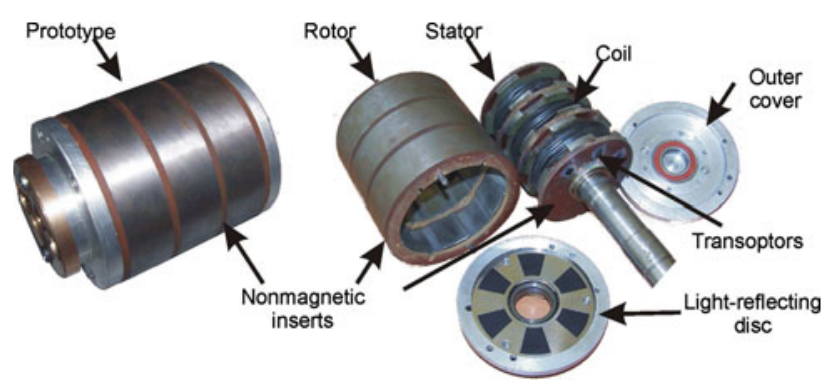

Fig. 1 Schematic of basic TFM prototype (prototype A)

Ranges of decision variables for construction optimization are analyzed in Sect. 4. An evolutionary algorithm (EA) for optimization of the magnetic circuit is outlined in Sect. 5, with various optimization criteria comparatively analyzed in Sect. 6. Final performance results for the optimized motor, with experimental verification on a constructed physical model are given in Sect. 7 and concluding remarks of Sect. 8 complete the paper. Some other details on modeling and construction optimization of TFMs can be found in Refs. $[12,13,17,18]$.

\section{Construction of a basic TFM prototype}

The basic motor prototype to be optimized (Fig. 1) consists of three equal modules, with the rotor sectors shifted between each other by ten mechanical degrees. Three stator modules are centered along the motor shaft. Each sector has six teeth and contains one phase belt. The modules are separated from each other with nonmagnetic inserts. The basic six-teeth TFM prototype is referred to as prototype A. The main specifications for the motor are given in Table 1 .

A simplified topology of circulation of the main flux is shown in Fig. 2, which illustrates the operation principle of the machine. The motor operates as a three-phase machine in the auto-piloted mode. The motor is supplied from a DC source through a three-pulse electric inverter. Control of the motor reduces to supplying the phases with a rectangular current waveform according to the sequence A,B,C,A.

Table 1 Specifications for TFM, prototype A

\begin{tabular}{ll}
\hline Supply voltage & $U_{n}=24 \mathrm{~V}$ \\
Rated current & $I_{n}=12 \mathrm{~A}$ \\
Rotational speed & $0 \div 300 \mathrm{rpm}$ \\
Winding & Three-phase \\
Number of turns & 130 \\
External diameter of rotor & $125 \mathrm{~mm}$ \\
External diameter of stator & $99.5 \mathrm{~mm}$ \\
Air gap & $\delta=0.5 \mathrm{~mm}$ \\
\hline
\end{tabular}

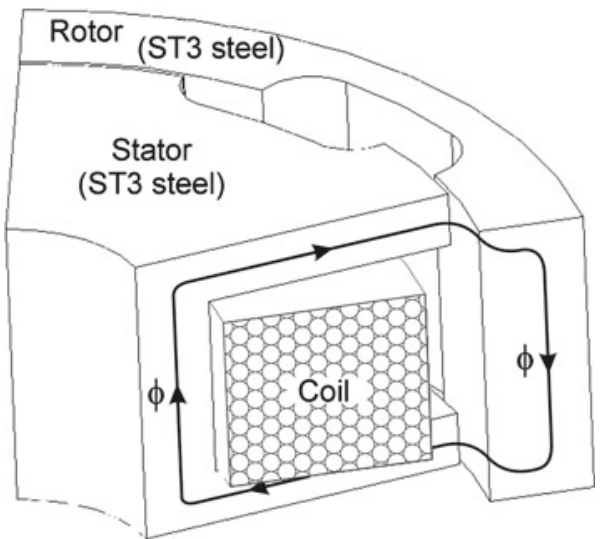

Fig. 2 Simplified topology of magnetic flux circulation

Connection of any phase results in adequate positioning of the rotor with respect to the stator (the teeth are aligned). Since the rotor sectors are shifted between each other, the successive connection of the phases causes the rotor to rotate. The connection of the successive phases is triggered by the signals from three transoptor sensors located in the external module. The sensors co-operate with a light-reflecting disc mounted onto an inner wall of the rotor.

It is worth mentioning that we have constructed the basic TFM prototype according to the state of the art as a result of long experience with earlier, low-quality prototype constructions $[12,17]$. However, formal optimization tools were not available to us at the time of constructing the basic TFM prototype. The basic motor (prototype A) will be used as a platform to verify the adequacy of a numerical model as well as a reference for the optimum TFM design.

\section{Numerical model of the basic TFM}

A numerical, FEM-based model of the basic motor was developed in Flux3D [12]. The 3D magnetostatic field was described using the method of scalar magnetic potentials. A simplifying assumption is introduced in the calculations that no magnetic couplings occur between the modules, which is justified by separation of the modules with the nonmagnetic inserts of an appropriate width. The assumption enables to limit the calculations to a single module only, and taking additionally account for the symmetry conditions in the motor, to $1 / 18$ of the motor volume, which is called a calculation segment or just a segment. The structure of the motor module and the discretization mesh for the numerical model are depicted in Figs. 3 and 4, respectively.

The electromagnetic torque is calculated by the virtual work method as a derivative of the magnetic co-energy with respect to the rotation angle between the rotor and stator. The rotation of the rotor versus stator is modeled by the sliding- 


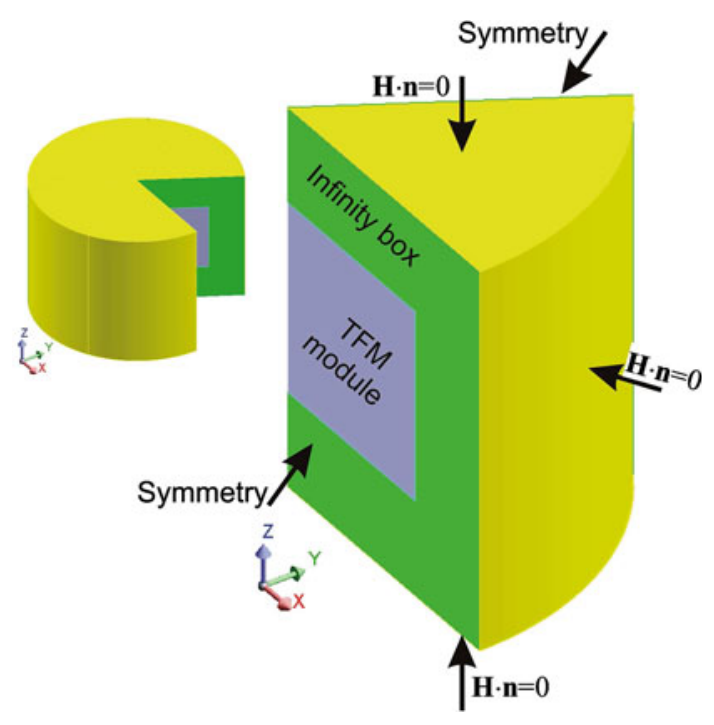

Fig. 3 Construction of TFM numerical model with boundary conditions

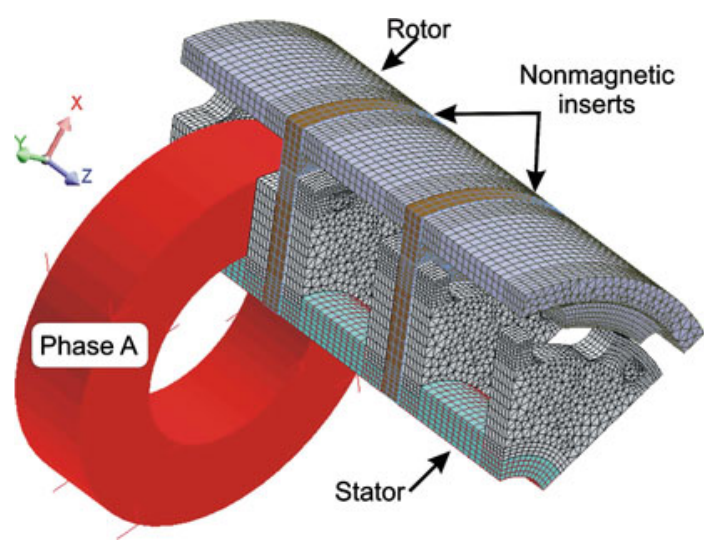

Fig. 4 Discretization mesh for TFM segment surface method [11,17]. In calculating the magnetic field, the approximated magnetizing curve for the electric steel is used according to Refs. [12,17].

The magnetic hysteresis and eddy currents are neglected in the calculations as well as a constant current density is assumed in the whole cross-section of the coils.

In a comparative analysis to follow, we will be interested in values of the average electromagnetic torque and the ripple torque. In a ripple torque-related analysis, we introduce a useful torque pulsation factor:

$\varepsilon=\left(\left(T_{\max }-T_{\min }\right) /\left(2 T_{a v}\right)\right) 100 \%$

where $T_{\max }, T_{\min }, T_{a v}$ denote the maximum, minimum and average values of the electromagnetic torque, respectively. The factor is based on the Electrotechnical Vocabulary, IEC 50-411, item 50-26, which has been brought to the authors' attention by one of the anonymous Reviewers.

Remark 1 Note that in the previous torque-related analyses $[17,18,20,25]$, the torque pulsation factor was defined as a doubled one in comparison to that of Eq.(1), thus giving unnecessarily rise to twice as higher relative pulsation figures.

The high performance of the numerical model for the basic TFM will be illustrated in comparison with its optimized version to follow.

\section{Analysis of decision variables for optimization}

Analysis of construction parameters of the magnetic circuit for the basic TFM is performed under the assumptions of a constant volume of the module and a constant external radius of the motor. The main construction parameters of the basic
Fig. 5 Cross-section of the TFM segment

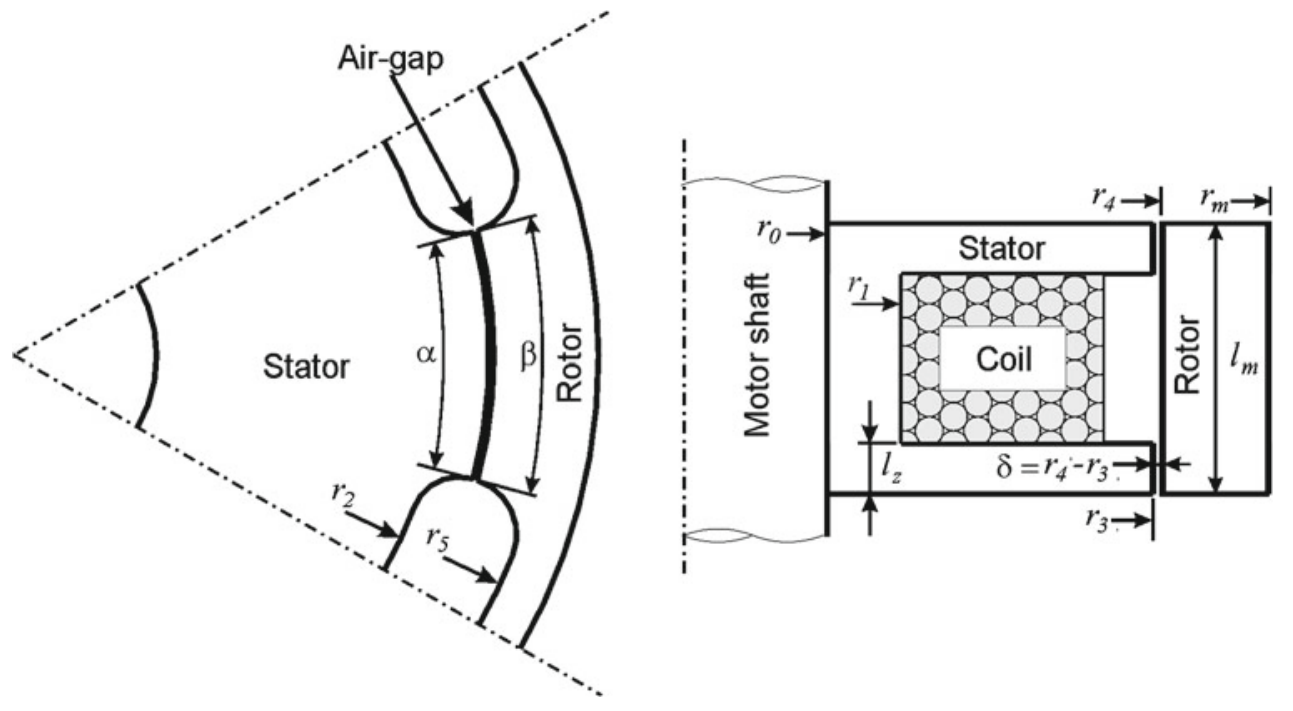


Table 2 Main construction parameters of the basic motor

\begin{tabular}{lllllllll}
\hline $\begin{array}{l}r_{0} \\
(\mathrm{~mm})\end{array}$ & $\begin{array}{l}r_{1} \\
(\mathrm{~mm})\end{array}$ & $\begin{array}{l}r_{2} \\
(\mathrm{~mm})\end{array}$ & $\begin{array}{l}r_{3} \\
(\mathrm{~mm})\end{array}$ & $\begin{array}{l}r_{4} \\
(\mathrm{~mm})\end{array}$ & $\begin{array}{l}r_{z} \\
(\mathrm{~mm})\end{array}$ & $\begin{array}{l}r_{m} \\
(\mathrm{~mm})\end{array}$ & $\begin{array}{l}l_{m} \\
(\mathrm{~mm})\end{array}$ & $\begin{array}{l}\alpha, \beta \\
\left({ }^{\circ}\right)\end{array}$ \\
\hline 15 & 23 & 42.50 & 49.75 & 50.25 & 6 & 62.50 & 32 & 30
\end{tabular}

Table 3 Calculated electromechanical parameters of the basic motor

\begin{tabular}{lllll}
\hline $\begin{array}{l}T_{\max } \\
(\mathrm{Nm})\end{array}$ & $\begin{array}{l}T_{\min } \\
(\mathrm{Nm})\end{array}$ & $\begin{array}{l}T_{a v} \\
(\mathrm{Nm})\end{array}$ & $\begin{array}{l}\varepsilon \\
(\%)\end{array}$ & $\begin{array}{l}L_{a v} \\
(\mathrm{mH})\end{array}$ \\
\hline 2.01 & 1.27 & 1.74 & 21.32 & 16.54 \\
\hline
\end{tabular}

TFM are shown in the cross-section of the calculation segment (Fig. 5) and specified for the basic motor in Table 2. Results of calculations of the main electromechanical (or integral) parameters for the basic motor are listed in Table 3, where we also include the average inductance $L_{a v}$ of the motor belt.

Now, we have the precise numerical model for the TFM but firstly, we are not quite sure which construction parameters are really meaning so that they could be chosen as decision variables for optimization and secondly, we do not know ranges of effective variations for the decision variables, the knowledge being crucial for possible reduction of a (very high) computational burden. The aim of this Section is to analyze how variations in the construction parameters affect the electromechanical parameters of the motor and to select a set of the decision variables, together with their variation ranges.

The influence of construction parameters on electromechanical parameters is analyzed for the basic machine with numbers of teeth in the stator and rotor being equal to 6 . A number of windings in the module belt are 130 and the current for which the calculations are made is equal to $12 \mathrm{~A}$. In order to properly assess the influence we introduce two additional, relative, electromechanical parameters $\Delta T_{a v}$ and $\Delta L_{a v}$, that is percentage changes in the average torque $T_{a v}$ and average inductance $L_{a v}$, respectively, with respect to those for the basic (or reference) motor. Due to space limitations we illustrate the said influence by one example only, namely variations in the parameters $r_{1}, l_{z}, \alpha$ and $\beta$, as shown in Table 4 , with the parameter variations denoted by the deltas. Full details on the results of the analysis of the said influence can be found in Refs. [12,13,17].

As a result of the above pre-optimization analysis, certain construction parameters are assessed to have only minor influence on the integral parameters of the TFM, so they are omitted in the optimum design. Finally, a vector of the decision variables is selected as $x^{\mathrm{T}}=\left[r_{1}, r_{2}, r_{3}, l_{z}, \alpha, \beta\right]$ (see Fig. 6) and variation ranges for each decision variable are specified. A 'reasonable' air gap is determined to be $\delta=$ $0.5 \mathrm{~mm}$.
Table 4 Integral parameters versus selected construction parameters $\left(r_{1}, l_{z}, \alpha\right.$ and $\left.\beta\right)$

\begin{tabular}{lllllll}
\hline$\Delta r_{1}(\mathrm{~mm})$ & 0 & 6 & 2 & 2 & 2 & 0 \\
$\Delta l_{z}(\mathrm{~mm})$ & 2.5 & 0 & 1 & 1 & 1 & 0 \\
$\Delta \alpha\left(^{\circ}\right)$ & -4 & -4 & 0 & -4 & -4 & 0 \\
$\Delta \beta\left(^{\circ}\right)$ & 0 & -4 & 0 & 0 & -4 & 0 \\
$T_{\max }(\mathrm{Nm})$ & 3.64 & 2.43 & 2.77 & 2.55 & 2.67 & 2.01 \\
$T_{\min }(\mathrm{Nm})$ & 1.45 & 1.67 & 1.94 & 1.01 & 1.00 & 1.27 \\
$T_{a v}(\mathrm{Nm})$ & 2.65 & 2.23 & 2.48 & 1.83 & 1.87 & 1.74 \\
$\Delta T_{a v}(\%)$ & 53.48 & 28.29 & 42.80 & 5.18 & 7.69 & - \\
$\varepsilon(\%)$ & 41.45 & 17.01 & 16.91 & 41.07 & 44.64 & 21.32 \\
$L_{a v}(\mathrm{mH})$ & 18.07 & 14.71 & 19.89 & 14.77 & 14.70 & 16.54 \\
$\Delta L_{a v}(\%)$ & 7.47 & -17.21 & 20.21 & -10.72 & -11.17 & - \\
$\Delta m_{F e}(\%)$ & 18 & 4 & 11 & 9 & 5 & - \\
$\Delta m_{C u}(\%)$ & 15 & 39 & 24 & 24 & 24 & - \\
\hline
\end{tabular}

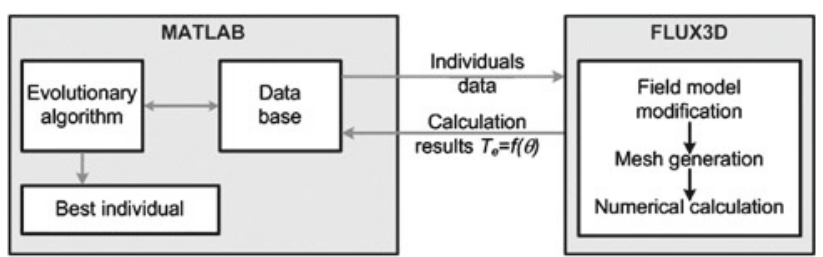

Fig. 6 General diagram of optimization process

Remark 2 It is worth mentioning that although the volume, outer diameter and air-gap length of the motor are kept constant during various design calculations, the active stator and rotor masses (copper, iron) may be subject to variations due to changes in the geometry for various constructions. Corresponding relative increases in the masses of iron and copper for the whole motor, $\Delta m_{F e}$ and $\Delta m_{C u}$, respectively, are shown in Table 4. These are quite low figures as compared to the improvements in the integral parameters as demonstrated in Table 4. As for the masses of iron for the stator only, their relative increases ranged from 18 to $45 \%$ for various motor versions.

Let us remember that the above analysis has been performed for the basic, physically existing six-teeth prototype (prototype A). We have repeated all the TFM model computations for some other numbers of motor teeth, which are illustrated in Table 5 in terms of the average torque only. For practical technological reasons, we have found the number of teeth equal to 12 as most reasonable for an ultimate, optimal TFM implementation. In that case, the numerical model is quite similar to the six-teeth case, but the symmetry conditions enable to limit the calculation segment to $1 / 36$ of the motor volume.

We have used the six-teeth prototype (A) for positive verification of the numerical model. Based on that model, we have designed (but not constructed!) a 12-teeth motor 
Table 5 Average torques for various numbers of teeth

\begin{tabular}{ll}
\hline Number of teeth & Average torque $(\mathrm{Nm})$ \\
\hline 6 & 1.74 \\
12 & 2.71 \\
18 & 3.28 \\
24 & 3.49 \\
\hline
\end{tabular}

prototype, 'equivalent' to A, to have a basis for final construction optimization (of the 12-teeth motor). Calculated construction and integral parameters for that basic 12-teeth motor model are specified, together with its optimized version, in Table 6.

\section{EA for optimization of the magnetic circuit}

Minimization of certain criteria functions is numerically performed making use of an evolutionary algorithm, being a generalization of a genetic algorithm [12,13,18]. Well-designed EA is known to have a (very) low probability to be stuck in a local minimum. The optimization tool, that is EA available in the MATLAB environment, is coupled with the Flux3D program used to design the magnetic circuit, which is depicted in Fig. 6.

Since field models are characteristic of a high computational burden, in particular for 3D FEM, the optimization algorithm is extended to include a database. The database is used to store data of individuals and the calculated electromagnetic torque. Prior to each field calculation cycle, the data base is searched to check up whether field calculations have already been made for the generated individual. In case such an individual has been found in the database, the magnetic field calculations are omitted. This enables to essentially reduce the computational effort as the execution times both for the save operation and searching the database are negligible when compared to the torque calculation times.

A number of computer simulation runs have been performed using our EA. The algorithm is set to operate on 20 individuals per population and a number of generations equal to $N=100$ are assumed as a stop condition for the algorithm.

\section{The impact of various optimization criteria}

Use of various, fitness-related optimization criteria has been analyzed in detail in Refs. [13,18]. Both high-torque and lowpulsation criteria have been examined and specific criterion functions have been recommended in specific TFM applications. Based on that analysis, a flexible criterion function has been introduced in Ref. [17], which is now extended to a new, more general, EA-related criterion:

$$
\begin{gathered}
\min _{\underline{x} \in X}\left\{\xi(\underline{x})=\left[C(i)+k\left(T_{a v} / T_{b}\right)^{2}\right.\right. \\
\left.\left.+(1-k)(1-\varepsilon / 100)^{2}\right]^{-1}\right\},
\end{gathered}
$$

where $T_{b}$ is the average electromagnetic torque for the basic (unoptimized) motor, $k \in[0.0,1.0]$ is the weighting coefficient, $C(i)$ is the variable weighting factor controlling the selective pressure of EA, with $i$ being the successive number of EA generations, and $X \subset \mathbf{R}^{6}$ is a subspace of admissible solutions related to variation ranges for the decision variables. We propose to use the exponential weighting function $C(i)=c_{0}\left(1-\lambda^{N-i}\right)$, where $c_{0}$ is the user-selected initial value (we use $c_{0}=1.0$ ), $N$ is the total number of EA generations $(i=1, \ldots, N)$ and the exponential weighting coefficient $\lambda \in(0.0,1.0)$ is typically selected close to 1.0 (we use $\lambda=0.96$ ). The objective/fitness function (2) provides a simple realization of the evolutionary design in multicriterial optimization.

The criterion (2) can serve a plethora of TFM construction optimization tasks, ranging from the maximum-torque ( $k=1.0)$ to the minimum-pulsation $(k=0.0)$ designs. Depending on a specific application of TFM the designer can select the weighting coefficient to cover either high-torque or low-pulsation solutions, or to compromise between the two. In Ref. [13], we have presented three instructive examples in which $k$ was selected to be $1.0,0.0$ and 0.5 , thus providing three different construction solutions for TFM. We recall the last example, with $k=0.5$, which can be translated to the requirement of both high torque and low pulsations. The impressive results on construction parameters versus integral parameters in Table 6 are self-explanatory (with bold values indicating the most important changes). This illustrates the power of both our new design approach and of the criterion (2) in the construction optimization of the TFM.

Table 6 Construction parameters and integral parameters for TFM before and after optimization according to (2)

\begin{tabular}{lcccccccccccc}
\hline & $\begin{array}{l}r_{1} \\
(\mathrm{~mm})\end{array}$ & $\begin{array}{l}r_{2} \\
(\mathrm{~mm})\end{array}$ & $\begin{array}{l}r_{3} \\
(\mathrm{~mm})\end{array}$ & $\begin{array}{l}l_{z} \\
(\mathrm{~mm})\end{array}$ & $\begin{array}{l}\alpha \\
\left({ }^{\circ}\right)\end{array}$ & $\begin{array}{l}\beta \\
\left({ }^{\circ}\right)\end{array}$ & $\begin{array}{l}T_{\max } \\
(\mathrm{Nm})\end{array}$ & $\begin{array}{l}T_{\min } \\
(\mathrm{Nm})\end{array}$ & $\begin{array}{l}T_{a v} \\
(\mathrm{Nm})\end{array}$ & $\begin{array}{l}\varepsilon \\
(\%)\end{array}$ & $\begin{array}{l}m_{F e} \\
(\mathrm{~kg})\end{array}$ & $\begin{array}{l}m_{C u} \\
(\mathrm{~kg})\end{array}$ \\
\hline Before optimization & 23 & 42.5 & 49.75 & 6 & 15 & 15 & 3.45 & 2.17 & 2.99 & 21.42 & 3.36 & 2.34 \\
After optimization & 27 & 43.5 & 51.75 & 7.5 & 15 & 12.5 & 5.66 & 4.03 & 5.18 & 15.68 & 3.72 & 3.15 \\
Change $(\%)$ & +18 & +2.4 & +2.5 & +25 & 0 & -17 & +64 & +86 & $+\mathbf{7 3}$ & $-\mathbf{2 7}$ & $\mathbf{9}$ & $\mathbf{3 4}$ \\
\hline
\end{tabular}




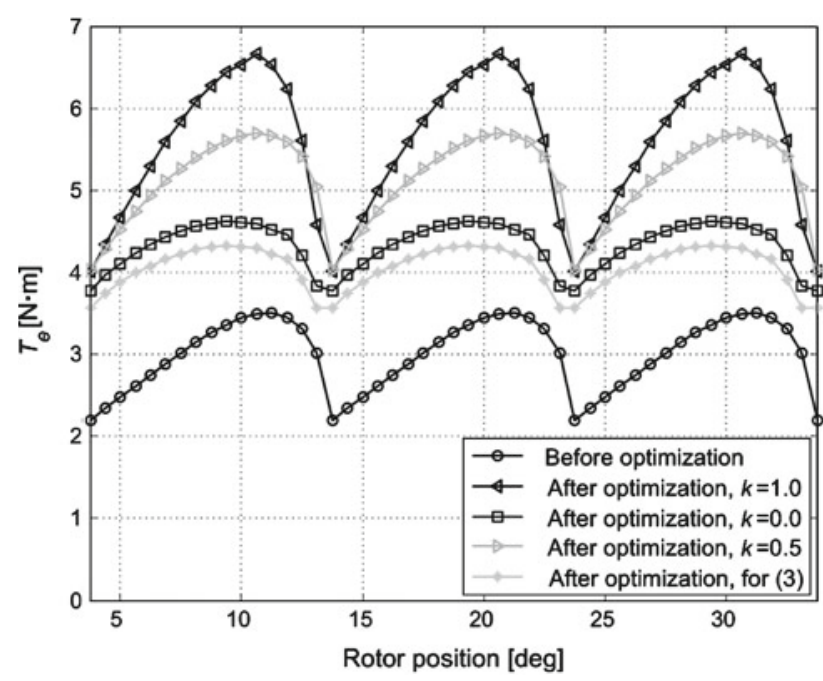

Fig. 7 Electromagnetic torque versus rotor rotation angle

Remark 3 It is interesting to note that, for the optimized 12-teeth version of the motor, the increases in masses of iron and copper for the whole motor, $m_{\mathrm{Fe}}$ and $m_{\mathrm{Cu}}$, respectively, were calculated to be equal to 9 and $34 \%$, respectively, which is specified in Table 6. Additionally, note that the increase in iron mass of the stator only was equal to $33 \%$.

The above three optimal solutions, that is for $k$ equal to 1.0, 0.0 and 0.5 , are now additionally compared in terms of plots of Fig. 7 of the electromagnetic torque versus rotor rotation angle. The value of the criterion (2) can also be appreciated from a comparison with an additional plot included, namely, for another criterion function:

$\min _{\underline{x} \in X}\left\{\zeta(\underline{x})=\left[T_{a v} /(s \varepsilon)\right]^{-1}\right\}$,

where $s$ is the standard deviation of the electromagnetic torque

$s=\left\{(1 /(n-1)) \sum_{i=1}^{n}\left(T_{e i}-T_{a v}\right)^{2}\right\}^{1 / 2}$,

with $T_{e i}$ being the value of the electromagnetic torque for the $i$ th angle of rotation of the rotor versus stator and $n$ is the number of the angles.

Clearly, the criterion (3), aiming at the simultaneous maximization of the electromagnetic torque and minimization of the ripple torque, is inferior to that of (2).

\section{The optimized physical model of the motor}

A new, optimized 12-teeth TFM prototype, called prototype B (see Fig. 8) was constructed according to the 'compromise' solution presented in the above Table 6 . Its average electromagnetic torque is increased by some $70 \%$ as compared to

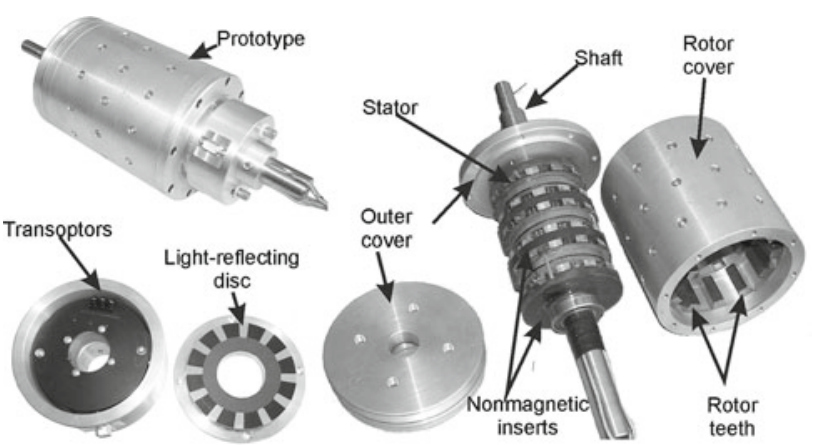

Fig. 8 Schematic of optimized TFM prototype (prototype B)

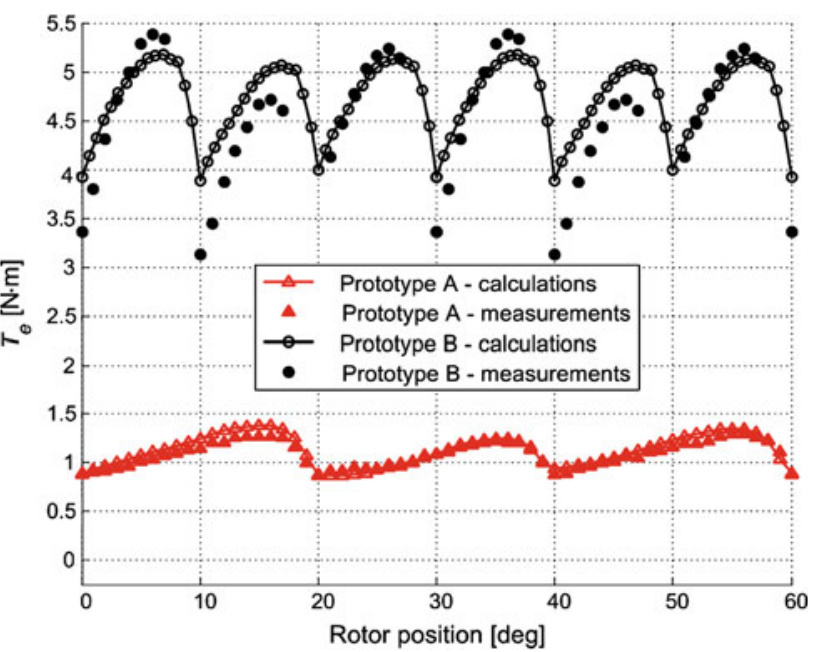

Fig. 9 Electromagnetic torque versus rotor rotation angle for basic and optimized TFM prototypes (A and B)

the basic (12-teeth) TFM prototype, with torque pulsations reduced by some $25 \%$ at the same time (compare with the simulation figures of 73 and $27 \%$, respectively).

Taking into account for the simplifying assumptions made at the modeling stage as well as some manufacture inaccuracy occurred in providing the specific air gap, the quality improvement for the optimized versus basic prototypes is really impressive. It is interesting to note that the external dimensions $\left(r_{m}, l_{m}\right)$ of the two considered motor prototypes $\mathrm{A}$ and $\mathrm{B}$ are the same.

For additional illustration of the final effect, Fig. 9 presents plots of the calculated/measured electromagnetic torque versus rotor position for the two constructed prototypes, that is the initial six-teeth prototype A and the final optimized 12-teeth prototype B. Note that the average torque for the latter is some $400 \%$ higher, with the ripple factor being two times lower and the static inductance some $10 \%$ higher.

Remark 4 The (subjective) comparison of prototypes A and $\mathrm{B}$ may raise doubts, in particular in terms of four-times higher torque for the latter. In fact, given the mmf and flux density, the force density is inversely proportional to the pole 
Table 7 Average torques $T_{a v}$ for various prototypes of the motor

\begin{tabular}{lll}
\hline & $\begin{array}{l}T_{a v} \text { for 6-teeth TFM } \\
(\mathrm{Nm})\end{array}$ & $\begin{array}{l}T_{a v} \text { for 12-teeth TFM } \\
(\mathrm{Nm})\end{array}$ \\
\hline Before optimization & 1.41 & 2.99 \\
After optimization & 2.64 & 5.18 \\
Change (\%) & +187 & +173 \\
\hline
\end{tabular}

pitch [10]. Well, but the prototype A is an initial, unoptimized six-teeth motor, whereas the prototype $B$ is an optimized 12-teeth machine. A more rational comparison of the prototypes is additionally given in Table 7 , which confirms the (approximate) doubling the torque against doubling the number of poles [10]. Also note that the figures in Table 7, related to the 6-teeth TFM before optimization and the 12-teeth TFM after optimization, are yielded from measurements on physical motor prototypes. It is worth mentioning at last that, referring to the 6- and 12-teeth stators, the doubled torque for the latter is connected with half-speed when supplying with same voltage (and frequency).

\section{Conclusions}

This paper has presented an effective solution to the problem of optimization of TFM construction parameters making use of a combination of a 3D FEM and an evolutionary algorithm. An optimum design enables to determine optimal construction parameters aiming at improved electromechanical parameters of the motor, which are represented here by high average electromagnetic torque and/or low ripple torque pulsations. In addition to advantageous effects of the evolutionary algorithm, the performance of the optimization process depends largely on a type of a criterion function used. The criterion function can be formulated in various ways for the same construction optimization task. A new flexible and effective criterion function has been proposed for the purpose, with a range of values of the weighting coefficient covering various optimal torque versus pulsation tasks, depending on specific applications of the motor.

The optimum construction design has been effectively applied in a new TFM prototype. Electromechanical parameters of the optimized prototype motor have been found very close to the theoretically calculated figures and much better than those for the basic, unoptimized prototype used as a reference. It is worth emphasizing once more that the numerical model has been developed for the initial, physically constructed 6-teeth prototype (A) and the construction optimization process has been implemented on the final, physically constructed 12-teeth prototype (B). This illustrates the versatility of the numerical model and the optimization procedure employed.
Acknowledgments Invaluable comments from anonymous reviewers are greatly appreciated.

Open Access This article is distributed under the terms of the Creative Commons Attribution Noncommercial License which permits any noncommercial use, distribution, and reproduction in any medium, provided the original author(s) and source are credited.

\section{References}

1. Arshad WM, Thelin P, Bäckström T, Sadarangani C (2004) Use of transverse-flux machines in a free-piston generator. IEEE Trans Ind Appl 40(4):1092-1100

2. Babazadeh A, Parspour N, Hanifi A (2004) Transverse flux machine for direct drive robots: modelling and analysis. In: IEEE conference on robotics. Automation and mchatronics, Singapore, vol 1, pp 376-380

3. Babazadeh A, Parspour N (2004) Analysis of shifted transverse flux reluctance motor. In: International conference on optimization of electrical and electronic equipment. Bravos, Romania, pp 53-58

4. Dubois MR, Polinder H, Ferreira JA (2002) Transverse-flux permanent magnet (TFPM) machine with toothed rotor. In: Proc. power electronics, machines \& drives conf, pp 309-314

5. Dubois MR, Dehlinger N, Polinder H, Massicotte D (2006) Clawpole transverse-flux machine with hybrid stator. In: International conference on electrical machines ICEM, Chania, Crete Island, Greece PSA, pp 4-11

6. Hur J, Kang GH, Lee JY, Hong JP, Lee BK (2003) Design and optimization of high torque, low ripple switched reluctance motor with flux barrier for direct drive. IEEE Trans Ind Appl 39(3):713-719

7. Husain I, Eshani M (1996) Torque ripple minimization in switched reluctance motor drives by PWM current control. IEEE Trans Power Electron 11(1):83-88

8. Jeong YH, Kang DH, Kim JM, Jang SM (2001) A design of transverse flux motor with permanent magnet shield. In: Proc. ISIE 2001, IEEE international symposium on industrial electronics, pp 995-999

9. Isastia V, Bellucci M (2004) A new configuration of a TFPM machine for a wheel motor. In: ICEM 2004 Cracow, vol 1, 5-8 September, pp 139-140

10. Kang DH, Chun YH, Weh H (2003) Analysis and optimal design of transverse flux linear motor with PM excitation for railway traction. IEE Proc 150(4):493-499

11. Kastinger G (2002) Design of a novel transverse flux machine. In: ICEM 2002 Brugge, August conf CD

12. Kowol M (2007) Performance analysis of an outer-rotor switched reluctance motor for light Vehicles in Polish. Ph.D. thesis, Opole University of Technology, Opole

13. Kowol M, Łukaniszyn M, Latawiec K (2008) Analysis of criterion functions in optimization of the magnetic circuit for TFM. In: International XVI symposium micromachines and servodrives MiS, Straszyn, Poland conf CD, 14-18 September

14. Koibuchi K, Ohno T, Sawa K (1996) An approach for optimal design of switched reluctance motor by finite element method. In: IEEE Conference on Electromagnetic Field Computation, pp 143-147

15. Lee W, Kim HS, Kwon BI, Kim BT (2004) New rotor shape design for minimum torque ripple of SRM using FEM. IEEE Trans Magn 40(2):754-757

16. Liuchen C (1996) Design procedures of a switched reluctance motor for automobile applications. IEEE Can Conf Electr Comput Eng 2:947-950 
17. Łukaniszyn M, Kowol M (2006) Influence of construction modification on the electromechanical parameters of the modular reluctance motor with outer rotor in Polish. Przegląd Elektrotechniczny Electrotechnical Survey R 82(11):43-45

18. Łukaniszyn M, Kowol M (2007) Optimization of magnetic circuit of a modular reluctance motor with an outer rotor Poznań University of Technology Academic Journals Electrical Engineering, pp 157- 166

19. Masmoudi A, Njeh A, Mansouri A, Trabelsi H, Elantably A (2004) Optimizing the overlap between the stator teeth of a claw pole transverse-flux permanent-magnet machine. IEEE Trans Magn 40(3):1573-1578

20. Nakata T, Takahashi N, Uehara K (1986) Analysis of magnetic characteristics of brushless DC motor taking into account the distribution of magnetization. IEEE Trans Magn 22(5):1084-1086

21. Sahin F, Ertan HB, Leblebicioglu K (2000) Optimum geometry for torque ripple minimization of switched reluctance motors. IEEE Trans Energy Convers 15(1):30-39
22. Sheth NK, Rajagopal KR (2003) Optimum pole arcs for a switched reluctance motor for higher torque with reduced ripple. IEEE Trans Magn 39(5):3214-3216

23. Viorel I, Jufer M, Crivii M, Viorel A (2004) Scaling procedure applied to the transverse flux motor. In: ICEM 2004, Cracow (Poland), paper PS2-20, 5-8 September 2004

24. Wang X, Du J, Ren N, Liu Z, Tang R (2006) Optimization of stator structure of transverse flux motor. J Iron Steel Res Int 13(Suppl 1):466-470

25. Wrobel R, Łukaniszyn M, Jagiela M, Latawiec K (2003) A new approach to reduction of the cogging torque in a brushless motor by skewing optimization of permanent magnets. Electr Eng 85(2): $59-70$ 